\title{
Role of dams on the floods of August 2018 in Periyar River Basin, Kerala
}

\author{
K. P. Sudheer ${ }^{1,2, *}$, S. Murty Bhallamudi ${ }^{1,3}$, Balaji Narasimhan ${ }^{1,3}$, Jobin Thomas ${ }^{1}$, \\ V. M. Bindhu ${ }^{1}$, Vamsikrishna Vema ${ }^{1,2}$ and Cicily Kurian ${ }^{1}$ \\ ${ }^{1}$ Department of Civil Engineering, Indian Institute of Technology Madras, Chennai 600 036, India \\ ${ }^{2}$ Department of Agricultural and Biological Engineering, Purdue University, West Lafayette, IN, USA \\ ${ }^{3}$ Indo German Centre for Sustainability, Indian Institute of Technology Madras, Chennai 600 036, India
}

Kerala state (India) experienced a devastating flood event during the month of August 2018. While an extreme rainfall event (ERE) was the primary reason for this flood, there was criticism at various levels that the authorities failed to manage the flood effectively through reservoir operations. One of the worst affected basins, Periyar River Basin (PRB), received a 145 year return period rainfall. This study reports the results and analysis of a modelling exercise using HEC-HMS to simulate and analyse the role of dams, as well as reservoir operations, on the flood of August 2018. The results indicated that the role of releases from the major reservoirs in the PRB resulting in the flood havoc was less. The analysis suggested that reservoir operations could not have helped in avoiding the flood situation as only $16-21 \%$ peak attenuation was possible by emptying the reservoir in advance, as the bulk of runoff to the flooding was also contributed by the intermediate catchments without any reservoirs to control. Further, the attenuated flood peak due to advance emptying of the reservoir would still be almost double the safe carrying capacity of the river section at Neeleswaram. In addition, the reliability of the rainfall forecast at higher lead times is also a concern for the reservoir operation. It is noted that the probability of EREs of this kind in the month of August in PRB is very small $(0.6 \%)$, and therefore any planned operation could not have helped in mitigating floods of such magnitude without a reliable EREs forecast coupled with reservoir inflow forecasting system and optimized set of reservoir operational policies.

Keywords: Extreme rainfall events, HEC-HMS, Kerala flood 2018, Periyar River Basin, reservoir operation.

EXTREME rainfall events (EREs) and associated floods causing substantial damage to mankind, infrastructure, and the physical environment are a subject of global con$\operatorname{cern}^{1-3}$. India has witnessed severe floods in the last two decades owing to EREs, among which the prominent ones are the events which occurred in Mumbai (Maharashtra in 2005), Kosi (Bihar in 2008), Krishna (Andhra Pradesh in

\footnotetext{
*For correspondence. (e-mail: sudheer@iitm.ac.in)
}

2009), Leh and Ladak (Jammu \& Kashmir in 2010), Kedarnath (Uttarakhand in 2013) and Chennai (Tamil Nadu in 2015). The extent of human and livestock mortalities, crop damages and economic losses due to the floods was enormous (www.ndma.gov.in/en/disasterdata-statistics.html). The total estimated loss due to the damages incurred during floods in India between 1953 and 2016 was estimated to be approximately INR 347,581 crores (www.cwc.gov.in/main/downloads/statewiseflood data damage statistics.pdf).

During August 2018, Kerala state (India) experienced some of the most severe EREs on record. This resulted in extensive flooding and landslides across most districts of the state, causing severe damage to both the built and natural ecosystems. According to the India Meteorological Department (IMD), the occurrence of the EREs in August 2018 was mainly due to formation of monsoon depressions over the Bay of Bengal and the westnorthwestward movement of the depression over coastal Odisha and neighbourhood (www.imd.gov.in/pages/ press_release.php dated 23 August 2018). On an average, Kerala received significantly high Indian summer monsoon rainfall (ISMR) from 1 June 2018 to 19 August $2018(2346.6 \mathrm{~mm})$, which is roughly $42 \%$ above the normal rainfall for the same period. Among the different districts of the state, Idukki received the maximum rainfall, which was almost $100 \%$ excess compared to the normal rainfall (3555 $\mathrm{mm}$ against the normal $1852 \mathrm{~mm}$ ). During the first 19 days of August 2018, Kerala received 164\% above normal rainfall, of which the major share was from two EREs during 8-10 and 14-19 in August 2018. The two rain gauge stations that realized maximum cumulative rainfall during 15-17 August 2018 was Peerumedu $(>800 \mathrm{~mm})$ and Idukki $(>700 \mathrm{~mm})^{4}$, both belonging to Idukki district in the Western Ghats. The highland physiography of Kerala supports numerous dams and reservoirs, which are predominantly designed for hydroelectric power generation as well as irrigation purposes. The state has experienced the onset of monsoon in the beginning of June 2018, and by the end of July 2018 most of the reservoirs in the state were almost near FRL ${ }^{4,5}$. This rare combination of the occurrence of the EREs, along with near full reservoir level (FRL) reservoir storages, made the 
situation challenging and compelled the authorities to open the gates of most of the dams in the state, which resulted in severe flooding in 13 out of 14 districts of the state $^{4}$. The extent of damage due to this flooding was preliminarily estimated to be to the tune of INR 20,000 crores $^{6}$. In addition, a loss of about 55,000 ha of agricultural land was also estimated as caused by the flood.

The role of dams and its operations in causing/ mitigating the flood have been criticized and debated in the scientific, social and political contexts, and the discussions, though mixed, explicitly held that the reservoir operations practiced during the flood and the lack of adequate warnings were responsible for the paroxysm (www.thehindu.com/sci-tech/energy-and-environment/reservoirs-not-managed-using-a-scientific-decision-support-system-m-rajeevan/article24785253.ece; www.thehindubusinessline.com/opinion/dams-did-exacerbate-keralas-floods/ article24988070.ece). The study ${ }^{5}$, based on the analysis of the IMD gridded rainfall data $\left(0.25^{\circ} \times 0.25^{\circ}\right)$ for the period 1901-2018 and reservoir storage information for seven major reservoirs of the state from India Water Resources Information System (WRIS) for the period 2007-2018 suggested that above normal seasonal rainfall (since 8 August 2018), maximum reservoir storage ( $\sim 90 \%$ of the FRL) prior to the EREs, and EREs in the upstream catchment areas of the reservoirs have worsened the flooding in Kerala. Central Water Commission (CWC, India) in its rapid assessment of the flooding situation in Kerala ${ }^{4}$ indicated that the reservoir releases during the ERE could not have been avoided as most reservoirs were near FRL, and the reservoir releases did not play any role in the extent of the flooding situation. The inference by $\mathrm{CWC}^{4}$ was based on the total quantum of flood generated to the storage capacity of the reservoirs, whereas the inference by the study ${ }^{5}$ was based on the observed record of reservoir storage. In both these studies, numerical simulation of floods under different reservoir storage scenarios has not been attempted. Hence, one main question remains unexplained: whether the early release of the water stored in the reservoirs would have attenuated the flood peaks, and if so, what would have been the extent of this attenuation? It is important to answer this question to (i) evolve a better policy for operating these reservoirs in the future and (ii) to find ways to minimize the flooding damage caused by EREs in this region.

Consequently, a hydrologic modelling based approach was used in this study to answer the above question in the backdrop of the flood events that occurred during August 2018. One of the major river basins that was severely affected by the 2018 flood in Kerala state was the Periyar River Basin (PRB), and the present study investigates the role of dams, as well as reservoir operations, in causing the flood in PRB. Periyar river system is regulated by 17 dams/barrages and reservoirs, and $80 \%$ of the hydroelectric projects of the state are located in the basin ${ }^{7}$. The flood events that occurred in PRB during August 2018 were numerically reconstructed in this study, and different scenarios of reservoir operation and antecedent conditions were analysed using the Hydrologic Modelling System of Hydrologic Engineering Centre, US Army Corps of Engineers (HEC-HMS).

\section{Materials and methods}

\section{Periyar River Basin}

The state of Kerala is located on the southernmost part of the west coast of India and is confined between the Western Ghats in the east and the Arabian Sea in the west. The state is unique as the onset of the ISMR normally starts over the Kerala coast, and the state belongs to one of the highest monsoon rainfall regions in India, along with the northeast India. The annual normal rainfall of the state is around $3000 \mathrm{~mm}$ with significant spatial variability across the state, and June and July months contribute the dominant share to the annual rainfall $(\sim 50 \%)^{8,9}$. Topography of Kerala shows wide diversity ranging from rugged and undulating highlands to gentle coastal plains, and the width of the state (i.e. mostly the distance between the ridgeline of the Western Ghats and the coastal line) varies between 15 and $120 \mathrm{~km}$. The gentle coastal plains of the state are densely populated, and the midland and the highland zones are predominantly utilized for various agricultural activities and commercial plantations. The narrow width of the state between the ridgeline of the Western Ghats and the coastal line along with dense population means, that the river basins have shorter response time to EREs and hence prone to severe flooding.

Periyar is the longest river in Kerala $(244 \mathrm{~km})$, and $\mathrm{PRB}$ is the second largest river basin of Kerala, with a catchment area of $5398 \mathrm{sq}$. km, and drains parts of Idukki and Ernakulam districts of the state (Figure 1). The basin has an inverted ' $L$ ' shape with a maximum width at the intersection. Major tributaries of the river are Mullayar, Cheruthoni Ar, Muthirapuzha, Perinjankutty Ar and Idamalayar, and most of the upstream tributaries flow through deep gorges and steep valleys. The general drainage pattern of the basin is dendritic in nature. The mainstream of the river bifurcates at Alwaye, and both the branches debouch into the Arabian Sea through two different estuaries. The north-trending branch joins the Chalakudy river and joins the Arabian Sea at Munambam through the Kodungallur-Azhikode estuary, whereas the south-trending branch forms numerous rivulets and joins the Vembanad-Kol wetland system and later joins the Arabian Sea through Cochin estuary.

Geologically, PRB has three distinct formations, such as crystalline rocks of Precambrian age, the Tertiary formations and the Quaternary deposits. The Precambrian 


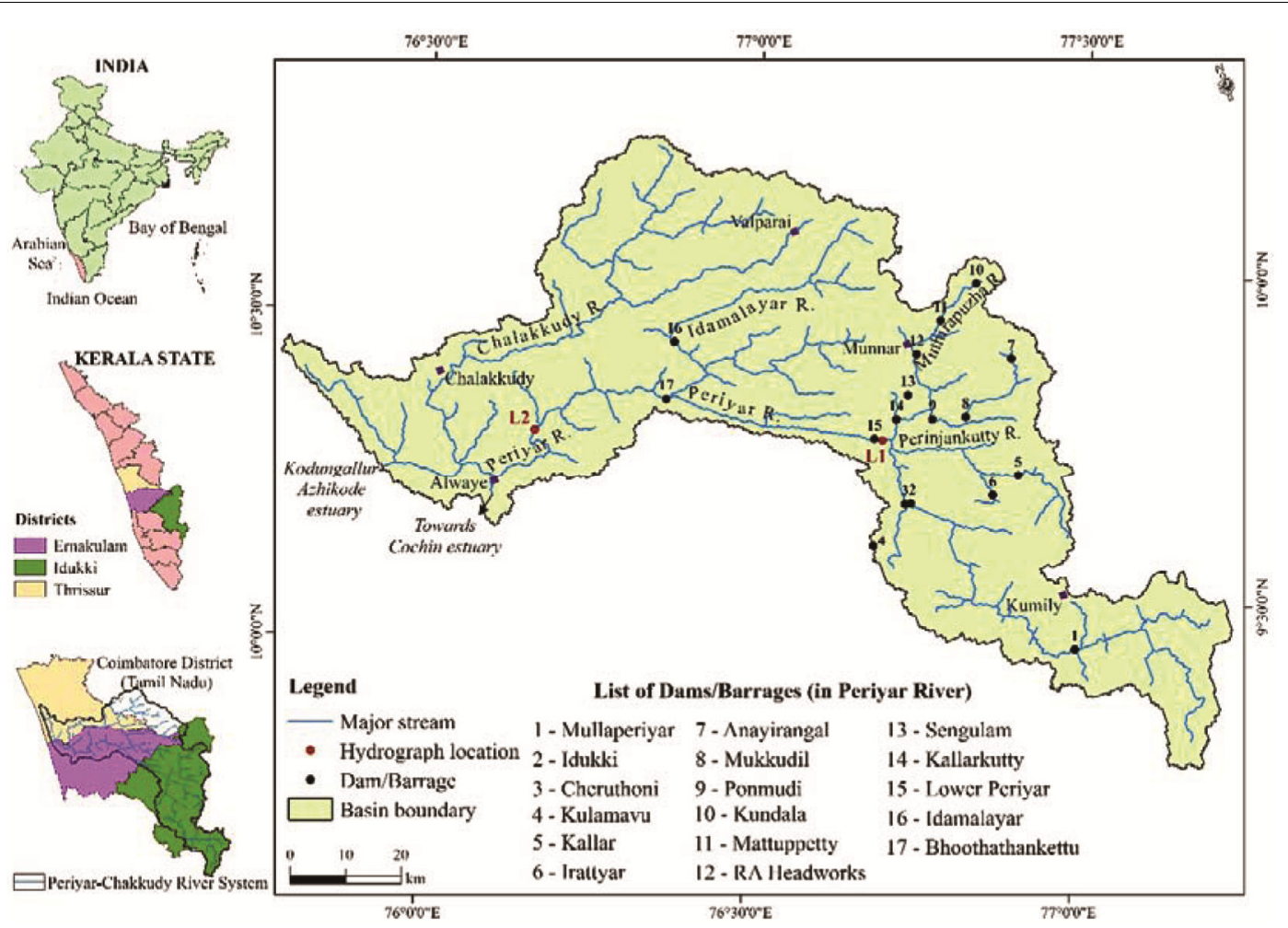

Figure 1. Periyar River Basin (including Chalakkudy River System), Kerala, India.

crystalline rocks are composed of the charnockite and migmatite groups (e.g. charnockites, charnockite gneiss, hypersthene-diopside gneiss, hornblende gneiss, and hornblende-biotite and quartz-mica gneiss/biotite gneiss), which are intruded by various felsic and mafic intrusives of age varying from Proterozoic to Tertiary. The sedimentary formations ranging in age from Eocene to Miocene (Vaikom, Quilon and Warkali beds) as well as Sub-Recent (laterite) to Recent (alluvium) overlie the crystallines along the coastal tract ${ }^{10,11}$. The river basin enjoys a tropical humid climate, with marked wet and dry seasons. The upstream parts of the basin (in Idukki district) receives a mean annual rainfall of about $3677 \mathrm{~mm}$, whereas the downstream parts (in Ernakulam district) experiences a mean annual rainfall of $3360 \mathrm{~mm}$. The annual rainfall of the upper parts of the basin reaches more than $5000 \mathrm{~mm}$, whereas the annual rainfall of the downstream parts ranges from 3233 to $3456 \mathrm{~mm}$. The mean monthly maximum temperature of the upstream portion ranges from $25^{\circ} \mathrm{C}$ to $32^{\circ} \mathrm{C}$ and minimum temperature from $14^{\circ} \mathrm{C}$ to $19^{\circ} \mathrm{C}$, while the mean monthly maximum temperature of the downstream part varies from $28^{\circ} \mathrm{C}$ to $32^{\circ} \mathrm{C}$ and the minimum ranges from $23^{\circ} \mathrm{C}$ to $26^{\circ} \mathrm{C}$ (refs 12,13 ).

Based on the observed data of CWC (Integrated Hydrological Data Book 2012), the mean annual runoff of Periyar river measured at Neeleswaram (L2 in Figure 1) was $6686 \mathrm{MCM}$. The measured daily discharge by CWC at L2 from 1971 to 2017 is shown in Figure 2, where the effect of ISMR is evident as the periodic highmagnitude discharges every year. It is also noticed that the duration of the lean flow period has considerably increased from 2010 onwards, compared to the previous years. The maximum daily discharge $\left(6324 \mathrm{~m}^{3} / \mathrm{s}\right)$ during 1971-2017 was measured on 5 August 2013, and $80 \%$ of the high-magnitude daily discharges $\left(>2000 \mathrm{~m}^{3} / \mathrm{s}\right)$ occurred either during the last week of July or during the first and second week of August.

The stream flow in PRB is heavily regulated by 17 dams and reservoirs (Table 1) and 2 barrages, which are constructed mainly for hydroelectric power generation as well as irrigation. The geographic location of these dams and barrages is depicted in Figure 1. The water level in the Idukki reservoir, the largest reservoir of the basin, is maintained by three dams, viz. Idukki, Cheruthoni and Kulamavu dams. Among the various dams, the largest dams are the Idukki-Cheruthoni-Kulamavu trio and the Idamalayar. The major irrigation projects in the basin are the Periyar Valley Irrigation Project, and the Idamalayar Irrigation Project. The major inter-basin transfer projects from PRB are the Mullaperiyar Dam (to Vaigai River, Tamil Nadu) and the Idukki Hydroelectric Project (to Muvattupuzha River, Kerala), and minor water transfer to Bharathapuzha river (Kerala) also co-exist in the basin.

\section{Hydrological modelling}

The hydrological simulation modelling of PRB was performed using HEC-HMS, which is a semi-distributed 
hydrologic model with the ability to perform continuous as well as event simulation in dendritic watershed systems. HEC-HMS is an advanced version of the HEC-1 model which was developed in 1968 by the US Army Corps of Engineers. Since then, HEC-HMS has been widely applied in hydrology to model the rainfall-runoff process $^{14}$, flood forecasting system planning ${ }^{15}$, assessing impact of land-use changes ${ }^{16}$ and runoff simulations in ungauged basins ${ }^{17}$. In HEC-HMS, the catchment is constructed by disintegrating the components of a hydrological cycle into manageable pieces, viz. precipitation, initial abstraction, evapotranspiration, infiltration, surface runoff and base flow. In this model, the physical description of the watershed is described using elements, viz. sub-basin, reach, junction, reservoir, diversion, source and sink. Computation proceeds from upstream to downstream direction and calculation of runoff are carried out in a sequential manner starting from canopy storage through surface or depression storage, infiltration and transform into base flow/surface flow hydrograph. Rainfall is the major input to this model along with other spatially distributed watershed characteristics, such as land use/land cover and soil, and the output from the model is the flow hydrograph.

Data used: The data used for setting up the HEC-HMS model for PRB were DEM, land use, soil and rainfall, and the details are given in the following sections.

The SRTM DEM (1 arc second; Figure $3 a$ ) was downloaded (www.earthexplorer.usgs.gov) and processed to generate the stream network and basin boundary of PRB. The voids present in the data were filled and the sinks were removed to create a seamless hydrologically

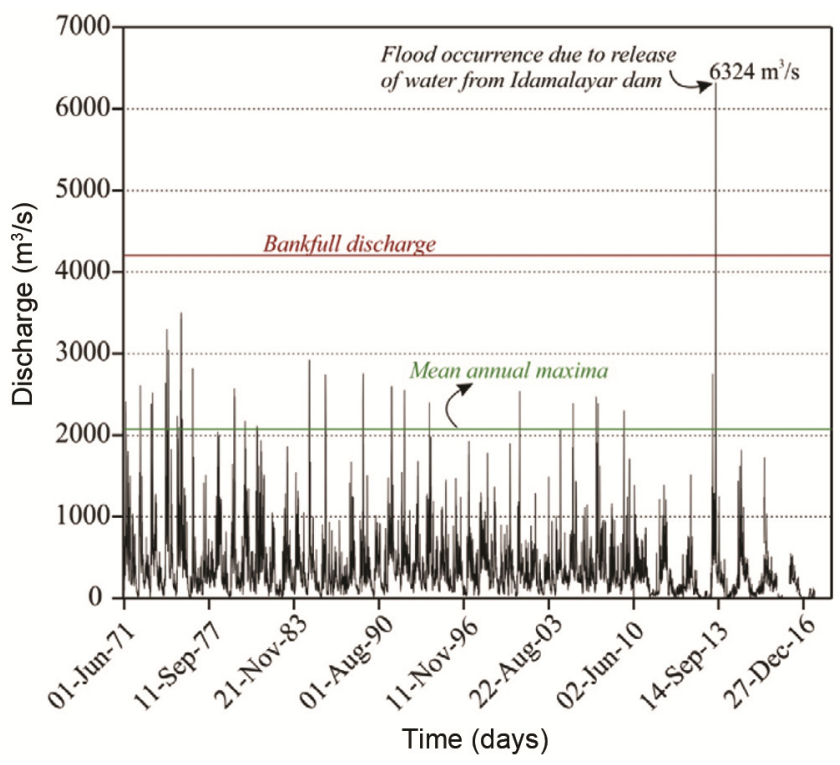

Figure 2. Daily discharge measured at Neeleswaram (L2 in Figure 1) by CWC (1971-2017). corrected DEM. The basin was subdivided into 144 sub-basins based on the topography and location of major reservoirs. The river basin covers diverse physiographic types, ranging from the highlands in the upstream, the lowlands and coastal plains in the downstream and the midlands in-between. Maximum elevation of the basin is $2690 \mathrm{~m}$ above msl (at Anai Mudi), which is the highest peak south of the Himalayas, and roughly $85 \%$ of the basin area belongs to the highlands physiography.

The land use/land cover types of PRB (Figure $3 b$ ) derived from IRS AWiFS data for the year 2010 with a
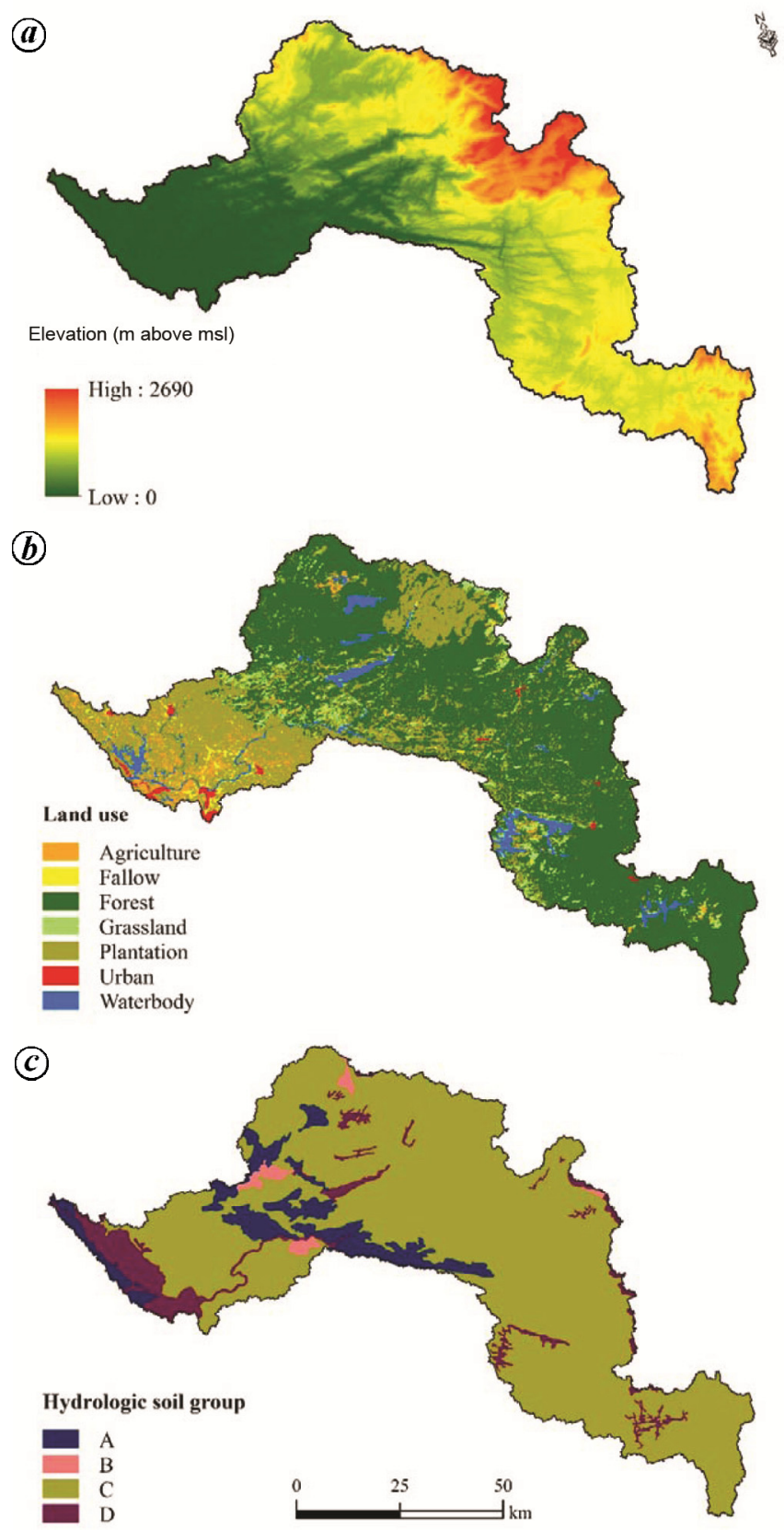

Figure 3. (a) DEM, (b) land use/land cover and (c) hydrologic soil group of PRB. 
Table 1. Selected dams in the Periyar River Basin

\begin{tabular}{|c|c|c|c|c|}
\hline Dam & Type & $\begin{array}{c}\text { Year of } \\
\text { completion }\end{array}$ & Length (m) & $\begin{array}{l}\text { Maximum height above } \\
\text { foundation }(\mathrm{m})\end{array}$ \\
\hline Mullaperiyar & G\&M & 1895 & 365.80 & 50.29 \\
\hline Idukki & G\&M & 1974 & 366.00 & 169.00 \\
\hline Cheruthoni & E/G\&M & 1976 & 651.00 & 138.38 \\
\hline Kulamavu & G\&M & 1977 & 385.00 & 100.00 \\
\hline Kallar & E/G\&M & - & 67.91 & 12.19 \\
\hline Irattayar & G\&M & 1989 & 146.30 & 19.81 \\
\hline Anayirangal & E & 1965 & 291.69 & 34.13 \\
\hline Ponmudi & $\mathrm{E} / \mathrm{G} \& \mathrm{M}$ & 1963 & 294.00 & 59.00 \\
\hline Kundala & E/G\&M & 1947 & 259.00 & 46.94 \\
\hline Mattuppetty & $\mathrm{E} / \mathrm{G} \& \mathrm{M}$ & 1957 & 237.74 & 85.34 \\
\hline Sengulam & E/G\&M & 1957 & 144.50 & 26.82 \\
\hline Kallarkutty & $\mathrm{E} / \mathrm{G} \& \mathrm{M}$ & 1962 & 182.88 & 43.00 \\
\hline Lower Periyar & $\mathrm{E} / \mathrm{G} \& \mathrm{M}$ & 1996 & 284.00 & 41.00 \\
\hline Idamalayar & E/G\&M & 1985 & 373.00 & 102.00 \\
\hline
\end{tabular}

E, Earthen; G, Gravity; M, Masonry. Source: WRIS-India.

spatial resolution of $60 \mathrm{~m}$ was obtained from the National Remote Sensing Centre (NRSC), Hyderabad. Major part of the basin is covered by forest, which is spread across the upstream and the central parts of the basin. The upstream parts are also covered by commercial plantations, such as tea, coffee, cardamom, whereas the coconut plantations and mixed crops (including spices, banana and tuber crops) dominate the remaining parts of the basin. Rubber is cultivated across the basin, irrespective of the physiographic domains, except in the high-altitude regions ( $>1500 \mathrm{~m}$ above $\mathrm{msl}$ ). Paddy cultivation is concentrated in the downstream parts of PRB and practiced along the flat regions of the valley and floodplains.

In general, four types of soil are seen in PRB, viz. forest soil, hill soil, laterite soil and alluvial soil. The upstream areas of the basin are dominantly covered by forest and hill soils. The forest soils are developed from crystalline rocks under forest cover, and depth of the soil column shows significant spatial variability depending on the degree of erosion and vegetative density. In general, the soils are characterized by sandy clay loam to clay textures. The hill soils are mainly distributed along the slopes of the denudation hills, with textures varying from loam to clay loam. The extent of forest and hill soils are limited to upstream and central parts of the basin, while laterite soils, interspersed with alluvial soils are dominated in the midlands and parts of downstream areas of the basin. The percentage of gravel content in the laterite soil is relatively high. Alluvial soils are developed from marine, lacustrine and riverine sediments or its combinations. The downstream portion of PRB is mostly covered by alluvial soils. The soil data used in HEC-HMS were collected from the National Bureau of Soil Survey and Land Use Planning $^{18}$. Based on the hydrologic soil group, most of the soils of the basin belong to class $\mathrm{C}$, followed by class A (Figure $3 c$ ). The poorly drained soils (Class D) are mainly distributed in the downstream parts, which have significant role in flooding.

Apart from the physical/topographical characteristics, spatio-temporal distribution of rainfall is also critical in quantifying the hydrologic response of the basin. However, due to lack of availability of time series of observed precipitation from the spatially-distributed rain gauges across the basin, the hydrological simulations of the current study were driven by satellite-derived precipitation data. The study employed half hourly cumulative gridded precipitation datasets of Integrated Multi-satellite Retrievals for GPM (IMERG) from 1 June to 31 August 2018 available at a spatial resolution of $0.1^{\circ} \times 0.1^{\circ}$ (www.pmm.nasa.gov/data-access/downloads/gpm). The IMERG data was bias-corrected using the simple ratio method with respect to the IMD rainfall from few selected rain gauges that were available to preserve the rainfall amount and spatial variability of the rainfall across the basin.

The distribution of the cumulative monthly rainfall of the basin shows considerable variability across space and time (Figure 4). Across PRB, the monthly rainfall during June varies between 50 and $1134 \mathrm{~mm}$, whereas the monthly rainfall during July (118 and $1596 \mathrm{~mm}$ ) and August (181 and $1686 \mathrm{~mm}$ ) is relatively high. The maximum rainfall in August 2018 (Figure 4c) occurred in the catchments of Idamalayar and Muthirapuzha basins.

HEC-HMS model setup: In this study, the basin files were prepared for PRB, using HEC-GeoHMS, which is the pre-processor unit of the HEC-HMS. The topographic information in terms of DEM and stream network was employed to delineate the sub-basins, along with attributes for each sub-basin in terms of area, slope, flow paths, centroid of the sub-basins, etc. Infiltration or loss 
from the rainfall was accounted using SCS curve number method (eq. (1))

$$
P_{e}=\frac{\left(P-I_{a}\right)^{2}}{P-I_{a}+S},
$$

where $P$ and $P_{e}$ are the accumulated and effective rainfall (in $\mathrm{mm}$ ) respectively, at time step $t, I_{a}$ the initial abstraction considered which is calculated using the relationship $\left(I_{a}=0.2 S\right)$ and $S$ is the potential maximum retention, i.e. the maximum amount of water which can be stored in the soil. $S$ is determined using the equation
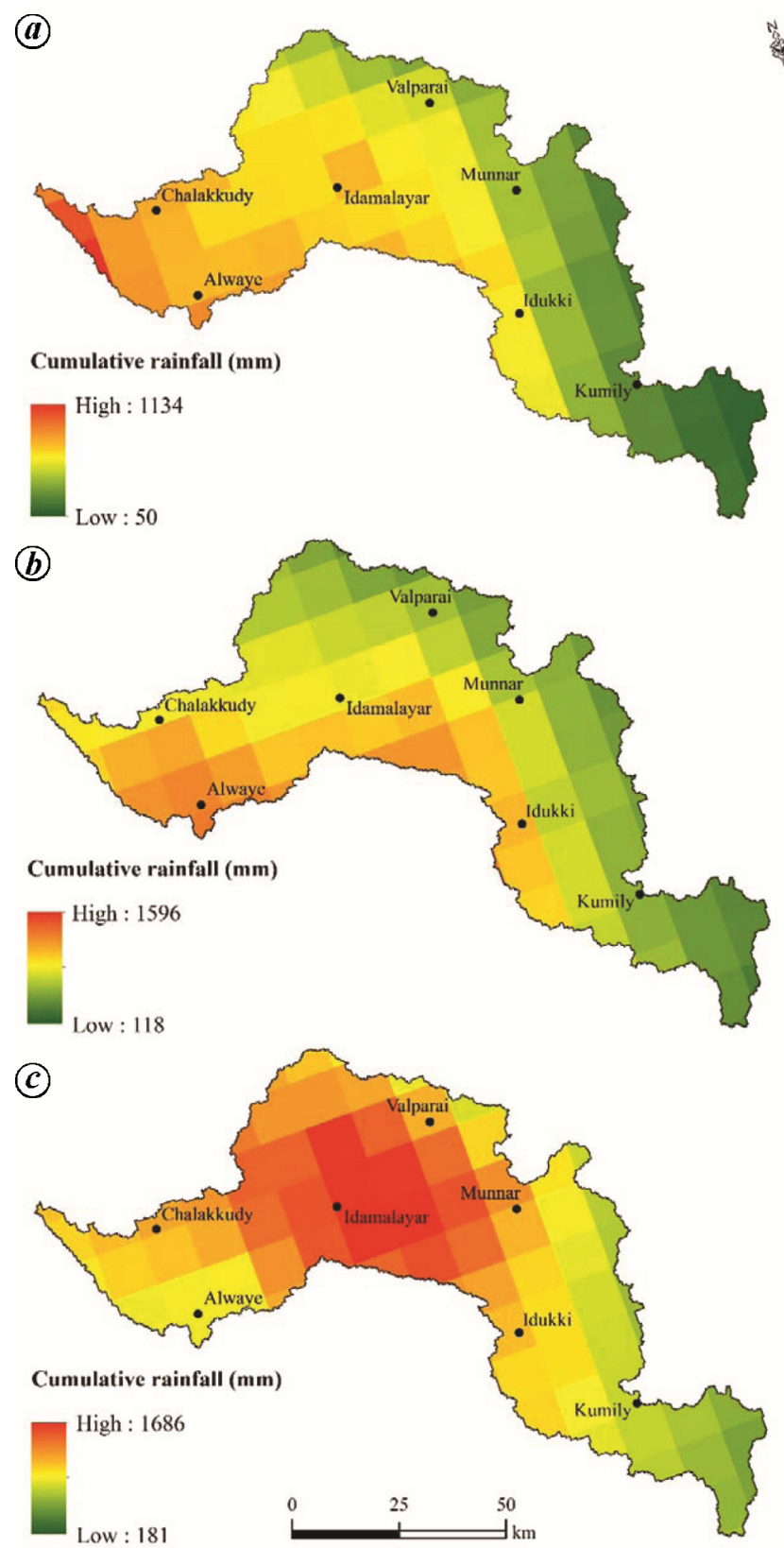

Figure 4. IMERG-based cumulative monthly rainfall in (a) June, (b) July and (c) August 2018 of PRB.

$$
S=\frac{25,400}{\mathrm{CN}}-254
$$

where $S$ is in $\mathrm{mm}$ and $\mathrm{CN}$ is the curve number, which is determined based on the land use/land cover and soil type of the area.

PRB was subdivided into 144 sub-basins, and a weighted value of $\mathrm{CN}$ for each of the sub-basin was assigned by considering the variability of land use and soil classes in the area. After estimating runoff volume using SCS curve number method, the transformation of runoff volume into hydrograph was done using SCS unit hydrograph method (SCS UH), which is an event based dimensionless hydrograph in which the discharge is expressed as a ratio of discharge $(q)$ to peak discharge $\left(q_{p}\right)$ (i.e. $\left.q / q_{p}\right)$ and time as a ratio of time $(t)$ to time to peak $\left(T_{p}\right)$ of the unit hydrograph (i.e. $t / T_{p}$ ]. For a given basin, the unit hydrograph is estimated using the peak discharge and lag time for the excess rainfall duration.
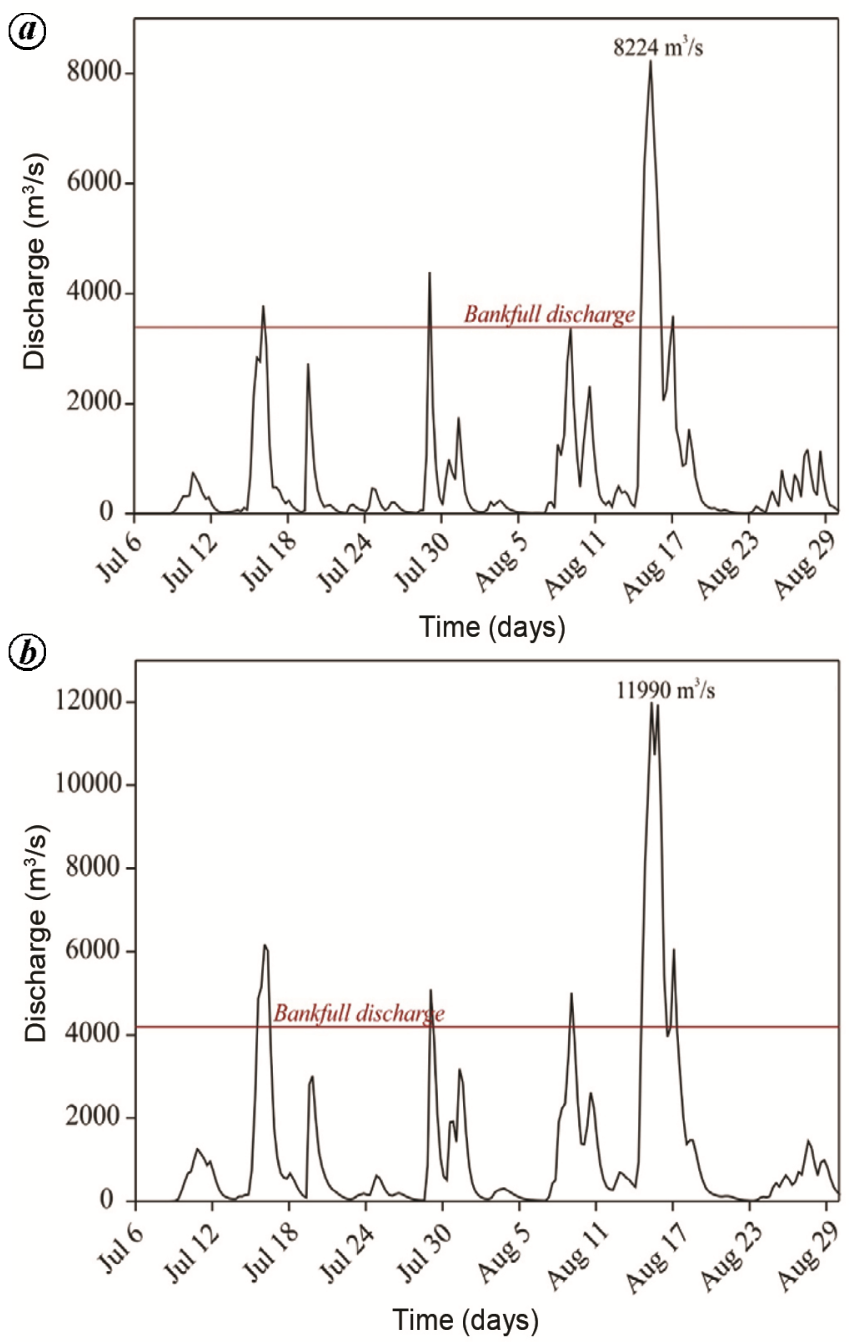

Figure 5. Hydrographs modelled by virgin simulation of the basin for (a) L1 and (b) L2. 
RESEARCH ARTICLES

Table 2. Description of the different scenarios used to model the hydrologic response of PRB

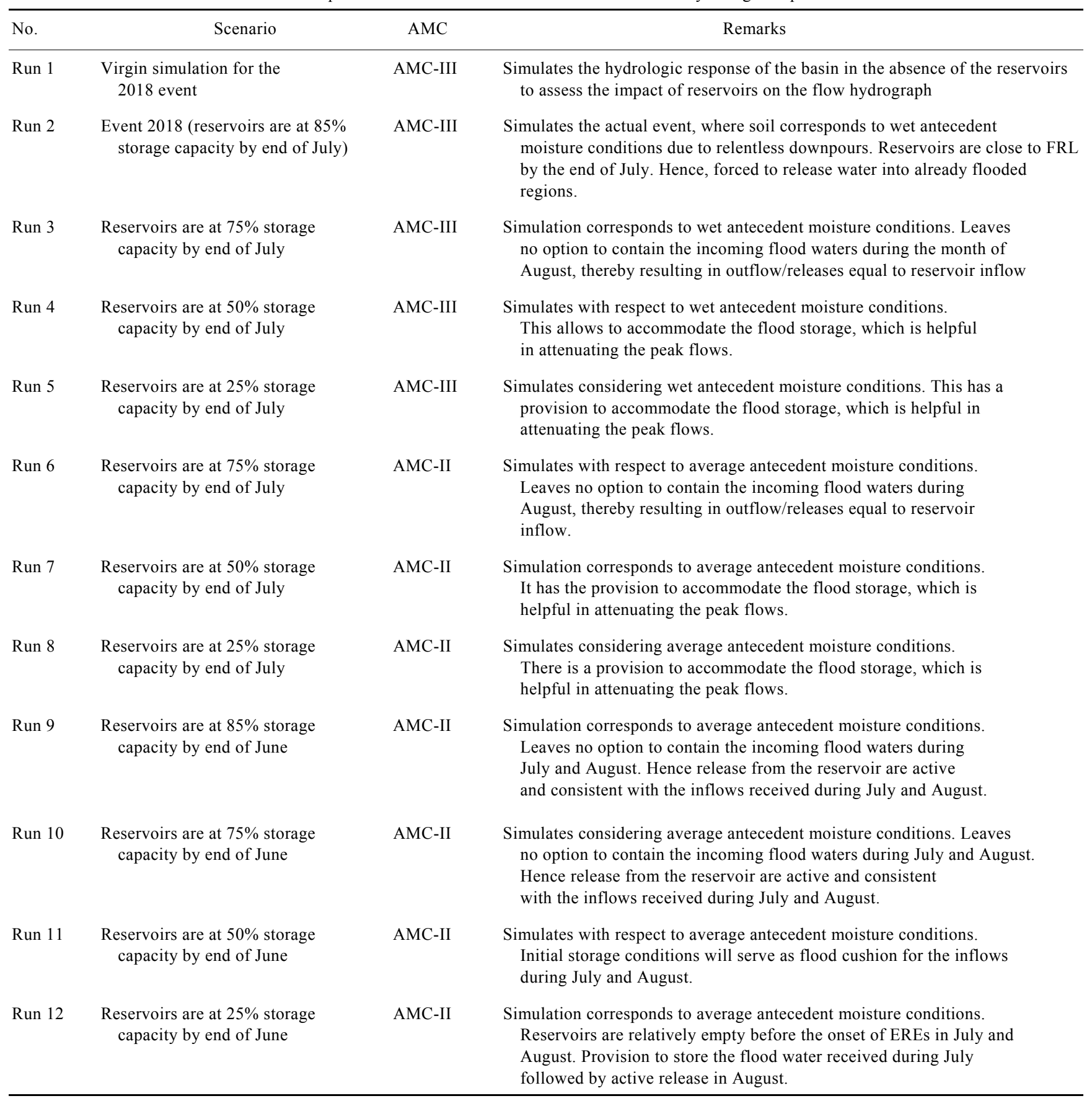

From the assumption that the area under the unit hydrograph should be equal to $1 \mathrm{~cm}$ direct runoff, it is shown that

$$
q_{p}=\frac{C A}{T_{p}},
$$

where $C=2.08$ and $A$ the drainage area in $\mathrm{km}^{2}$ and $q_{p}$ is expressed in $\mathrm{m}^{3} / \mathrm{s} \mathrm{cm}$. $T_{p}$ (in hours) can be expressed as

$$
T_{p}=\frac{t_{r}}{2}+t_{p},
$$

where $t_{r}$ is the duration of effective rainfall (in hours) and $t_{p}$ is the lag time (in hours), which is approximated to $0.6 T_{C}\left(T_{C}\right.$ is time of concentration of watershed).

The methods selected for modelling the components of runoff process are SCS curve number (loss method), SCS unit hydrograph (transform method) and kinematic wave method (routing option). These methods are selected based on the availability of data, suitability for the hydrologic condition, and the number of parameters (minimum) involved in modelling the process. For routing by kinematic wave method, information pertaining to river cross 
sections such as shape of the cross section, width of the channel, length of the reach, etc. needs to be collected. In this study, the river cross section information was extracted from SRTM DEM (1 arc sec) and was later verified using Google Earth by overlaying the information extracted from the DEM. In addition, the extracted cross section information at Neeleswaram (discharge gauging site maintained by $\mathrm{CWC}$ ) has been verified with measured cross section, and is found to match closely. Manning's roughness $(n)$, which is a parameter required for kinematic wave routing was arrived at by field observation of the stream characteristics at various locations.

The model parameters such as curve number $(\mathrm{CN})$ and lag time $\left(t_{p}\right)$ were extracted from land-use and soil map, along with the hydrologic soil groups and soil characteristic information. Based on the land-use data and the soil information, the lumped $\mathrm{CN}$ value and $t_{p}$ for each subbasin were generated by HEC-GeoHMS. The default parameters thus derived were further fine-tuned so as to match the simulated hydrograph closely with the observed hydrograph reported at the CWC gauging site (Neeleswaram). The parameters for each of the methods in the HEC-HMS were kept constant throughout the analysis of different scenarios.

Scenarios: The flooding in PRB was simulated using different combinations of reservoir storages and antecedent soil moisture conditions (AMC) to assess hydrologic response of the basin to varying boundary conditions. As part of the study, twelve scenarios were simulated, which are given in Table 2 .

Two control locations (L1 and L2 in Figure 1) were selected to generate the flood hydrograph for analysis. L1 is downstream of the confluence between the Periyar and Muthirapuzha rivers, and L2 is a downstream location in the PRB, where the gauge site (Neeleswaram) is maintained by CWC.

\section{Results and discussion}

\section{Virgin simulation run for the 2018 event (run 1)}

To understand the effect of regulation of stream flow in PRB by dams and barrages, a scenario was modelled in HEC-HMS without considering the dams and reservoirs (i.e. virgin simulation), and the entire basin was treated as unregulated. The simulated hydrographs with the EREs of 2018 for the virgin run shows peak discharges of $8,224 \mathrm{~m}^{3} / \mathrm{s}$ and $11,990 \mathrm{~m}^{3} / \mathrm{s}$ at L1 (Figure $5 a$ ) and L2 (Figure $5 b$ ) respectively.

\section{Simulation of the flood events of August 2018 (run 2)}

The catchment area of Periyar river witnessed relentless rains beginning from June 2018, resulting in the reservoir storage to FRL by end of July ${ }^{4}$. The continuous spell of rainfall from July 6 has already made the soil of the basin saturated, and the EREs that occurred in August resulted in higher runoff than under-average conditions. This wet antecedent condition was simulated by assuming AMCIII condition as per the SCS curve number method with appropriate $\mathrm{CN}$ values. Idukki and Idamalayar reservoirs of the PRB have live storage capacities greater than $1000 \mathrm{MCM}$ (i.e. $1460 \mathrm{MCM}$ and $1018 \mathrm{MCM}$ respectively). Since the reservoirs were near FRL by the end of July, the selected simulation time period was from 1 August 2018 to 31 August 2018 to represent the actual conditions prevalent within the basin.

The time step, which was less than the time of concentration $\left(T_{C}\right)$ of individual sub-basins was adopted to ensure that peak flows were effectively captured by the model. The HEC-HMS run was performed with curve number corresponding to AMC-III and reservoir storage levels at $85 \%$ at the beginning of model run on 1 August 2018. The hydrograph locations, where the flow hydrographs were extracted from the HEC-DSS database of the model run are: (a) inflows to Idukki reservoir, (b) location 1 (L1), which captures the releases from Idukki reservoir along with the hydrologic response of the upstream catchments within Idukki district, and (c) location 2 (L2) at Neeleswaram (where a CWC stream gauge site is located), which captures releases from Idukki and Idamalayar reservoirs along with the free catchment response. Figure $6 a-c$ shows the flow hydrographs simulated at the control points for the time period 1-31 August 2018. Since the observed hydrograph except at $\mathrm{L}^{4}$ is at six hourly intervals, the simulated flows were also generated at intervals of $6 \mathrm{~h}$ to compare the model simulated and the observed flow hydrographs (Figure $6 a$ and $c$ ).

The HEC-HMS simulated the peak inflow of $2763 \mathrm{~m}^{3} / \mathrm{s}$ to Idukki reservoir on 15 August 2018 at $20: 00 \mathrm{~h}$, and the maximum release of $1860 \mathrm{~m}^{3} / \mathrm{s}$ on 15 August $20: 00 \mathrm{~h}$ (Figure $6 a$ ). The measured peak inflow to the reservoir and the release were $2532 \mathrm{~m}^{3} / \mathrm{s}$ and $1614 \mathrm{~m}^{3} / \mathrm{s}$ (15 August $22: 00 \mathrm{~h}$ ) respectively. A comparison of the measured and modelled peak discharges exhibited less than $10 \%$ deviation, which indicates that the model captured the flood event reasonably well in terms of the peak discharge and releases from the reservoirs.

Figure $6 b$ is the simulated flow hydrograph at L1, where magnitude of the peak flow reached up to $5523 \mathrm{~m}^{3} / \mathrm{s}$. Since $\mathrm{L} 1$ does not have observed records, the simulated hydrograph was not compared to assess the accuracy of the representation of the hydrograph. Figure $6 c$ shows the flow hydrograph (simulated versus observed) at L2, which geographically corresponds to the CWC gauging site in the downstream of Periyar river. HEC-HMS generated a maximum discharge of $9965 \mathrm{~m}^{3} / \mathrm{s}$, while the observed peak discharge was $8800 \mathrm{~m}^{3} / \mathrm{s}$. A quantitative comparison between the modelled and the 


\section{RESEARCH ARTICLES}

observed hydrographs for 14-18 August evidently suggests realistic agreement. The difference in the magnitude of the peak discharges (i.e. $12 \%$ over-prediction by the model) can be attributed to the differences in the rainfall occurred and IMERG precipitation data and the model parameter uncertainty to a certain extent. In addition, the possible anomalies in the river cross section information that is extracted from the DEM could also lead to some level of inaccuracy in the simulated flow, though found
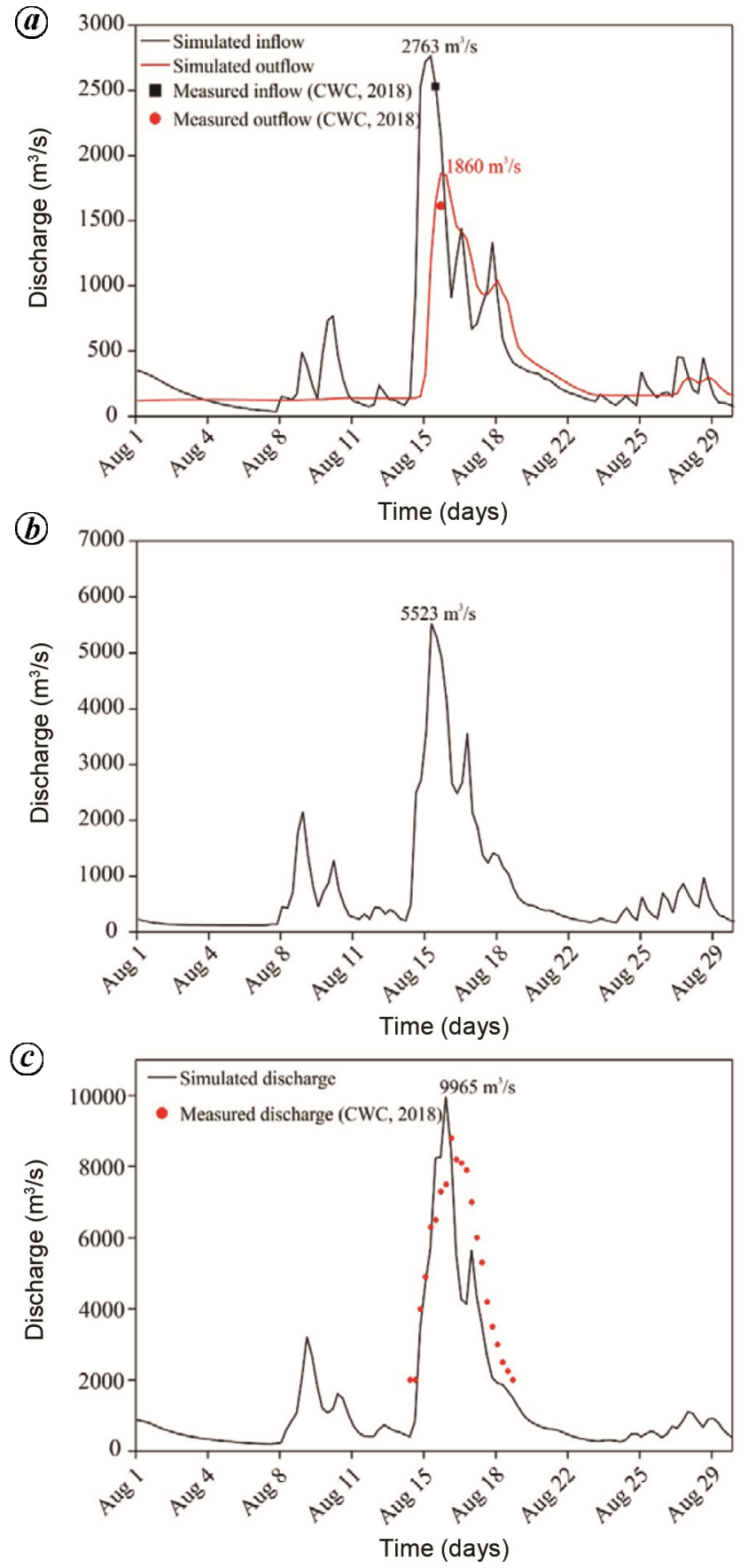

Figure 6. Simulated hydrographs at (a) Idukki reservoir, (b) location 1 (L1) and (c) location 2 (L2). Simulated flows were compared at Idukki reservoir and L2 with measured flows ${ }^{4}$. to be very minimal during a sensitivity analysis. The numerous landslides which occurred in PRB during the EREs $^{6}$ could have altered the hydrologic response of the catchment, which may also be a reason for the differences in the peak flow estimates. Compared to virgin simulations, which resulted in peak flow magnitudes 8,224 and $11,990 \mathrm{~m}^{3} / \mathrm{s}$ at L1 and L2 respectively (Figure $5 a$ and $b)$, it can be observed that the reservoirs were effective in reducing the peak flows to the scale of $2500 \mathrm{~m}^{3} / \mathrm{s}$.

It is noted that the peak discharge at L2 was $9965 \mathrm{~m}^{3} / \mathrm{s}$ (Figure $6 c$ ), while the maximum release from the Idukki reservoir was only $1860 \mathrm{~m}^{3} / \mathrm{s}$ (Figure $6 a$ ). Therefore a major share of the peak flow at L2 is contributed by the catchment area of the major tributaries, such as Perinjankutty, Muthirapuzha and Idamalayar. In order to assess the contributions from the different tributaries, the flow hydrographs generated along the four major branches of the Periyar river were plotted along with the hydrograph generated at L2 (Figure 7). The relative magnitude of individual hydrographs that can be inferred from Figure 7 points to the observation that EREs, coupled with saturated soil moisture conditions and physical characteristics of the catchment, had significant contribution in the flow hydrograph simulated at L2. A quantitative comparison indicates that the hydrologic response of the major tributaries of the Periyar river was also significant in terms of magnitude of flows, compared to the reservoir releases. For example, the flood discharges from the tributaries such as Perinjankutty $\left(3500 \mathrm{~m}^{3} / \mathrm{s}\right)$, Idamalayar $\left(2828 \mathrm{~m}^{3} / \mathrm{s}\right)$ and Muthirapuzha $\left(2037 \mathrm{~m}^{3} / \mathrm{s}\right)$ were comparably higher than the release from Idukki reservoir $\left(1860 \mathrm{~m}^{3} / \mathrm{s}\right)$. This indicates that the role of releases from Idukki reservoir in causing the flood havoc was less, as Perinjankutty river, which is nearly uncontrolled,

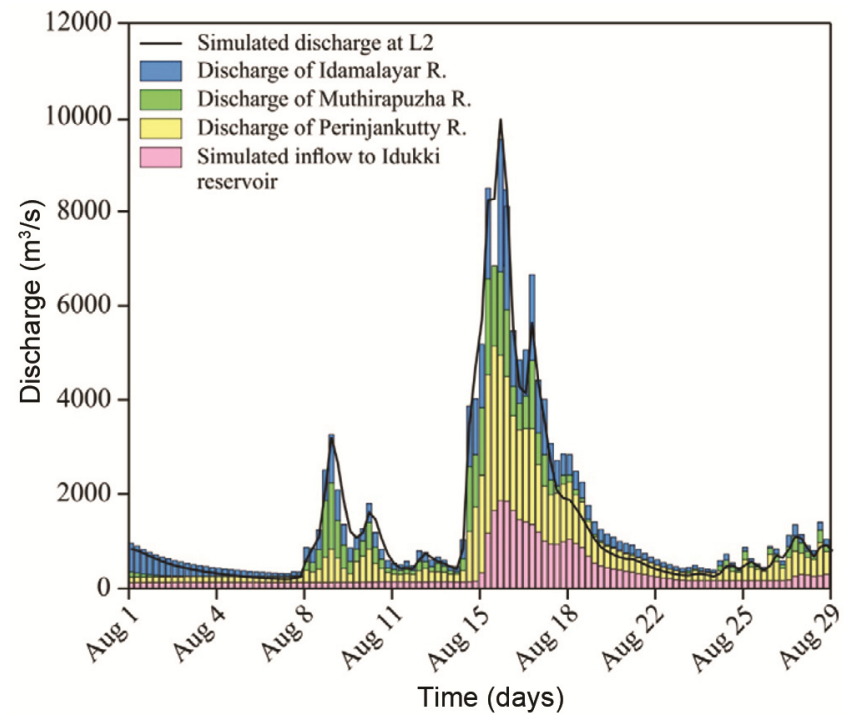

Figure 7. Comparison of simulated flow hydrographs along the major tributaries of the Periyar river and L2. 
contributes almost twice the amount of release from Idukki reservoir.

\section{Comparison of different scenarios (runs 3 to 12)}

The flood that occurred in PRB was simulated with respect to varying scenarios of reservoir storage capacities at different timelines and different soil moisture condi-
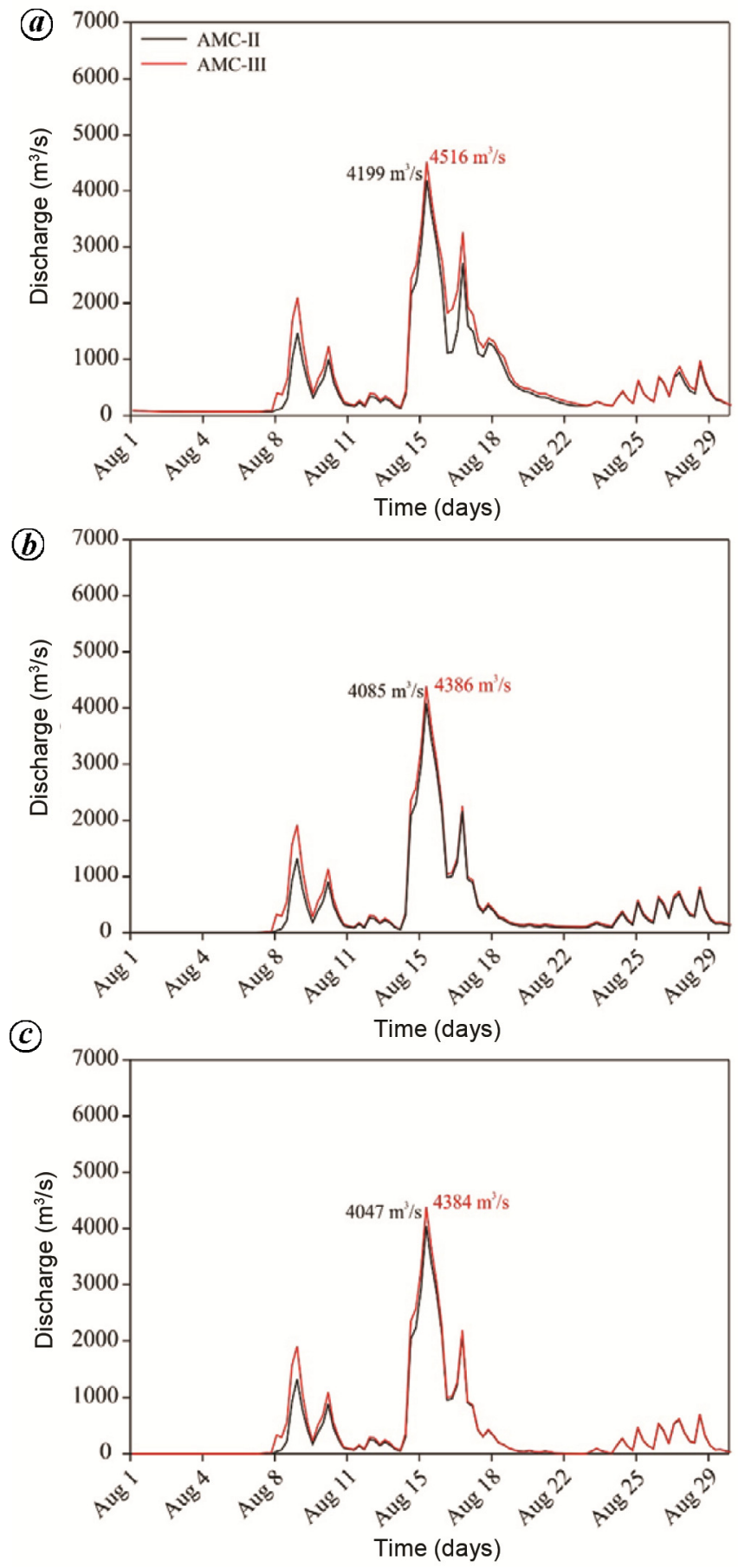

Figure 8. Flood hydrographs at L1 when reservoirs are at storage capacities (a) $75 \%$, (b) $50 \%$ and (c) $25 \%$ by the end of July 2018 with AMC-II and AMC-III conditions. tions. Figures 8 and 9 show the flow hydrographs corresponding to varying storage capacities (i.e. $75 \%, 50 \%$ and $25 \%$ ) at the end of July 2018 under AMC-II (average) and AMC-III (wet) conditions at L1 and L2 respectively. It is noted that the antecedent soil moisture condition does not have significant influence on the simulated peak flow as the difference in magnitude between both the cases (Figures 8 and 9) is found to be within 10\%.
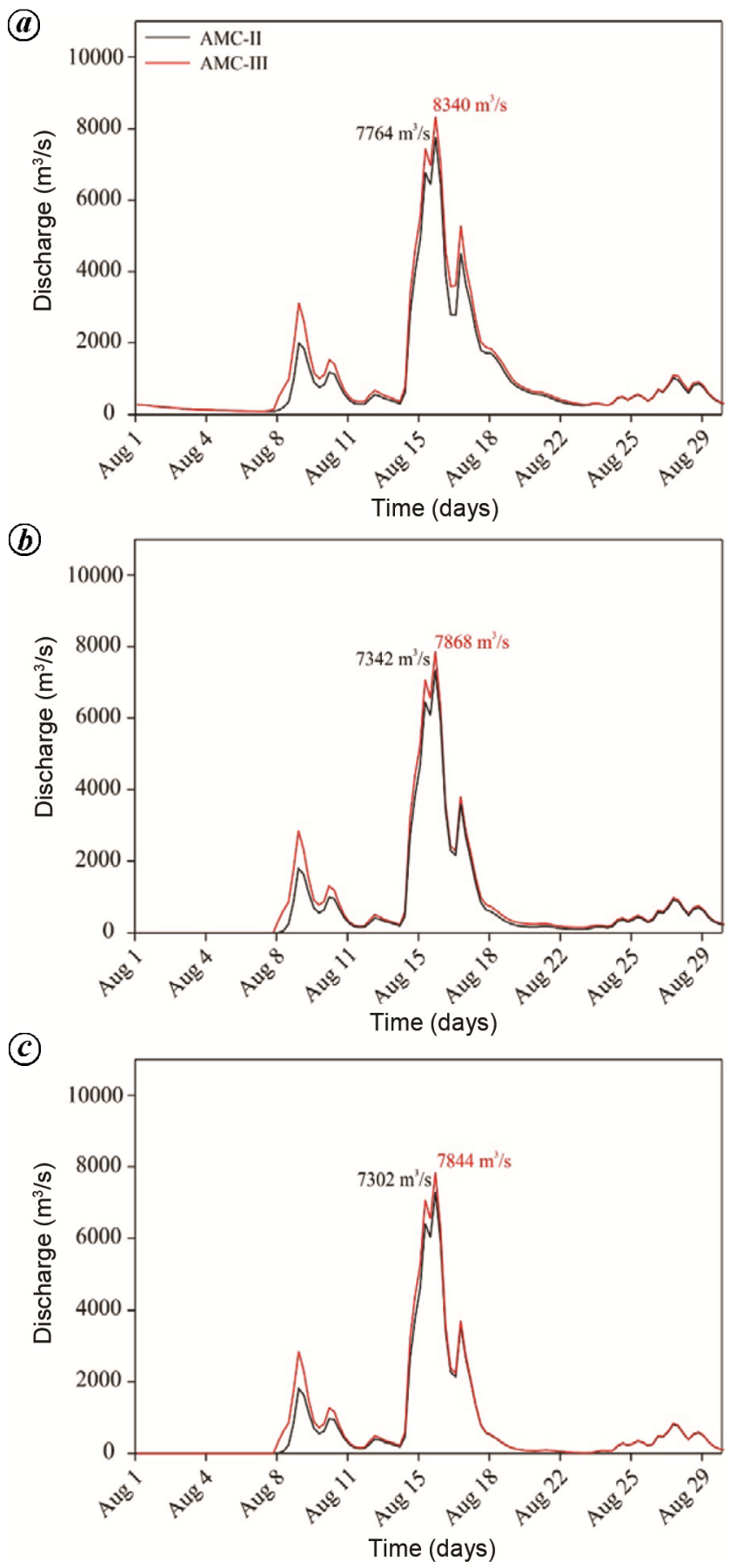

Figure 9. Flood hydrographs at L2 when reservoirs are at storage capacities (a) $75 \%$, (b) $50 \%$ and (c) $25 \%$ by the end of July 2018 with AMC-II and AMC-III conditions. 

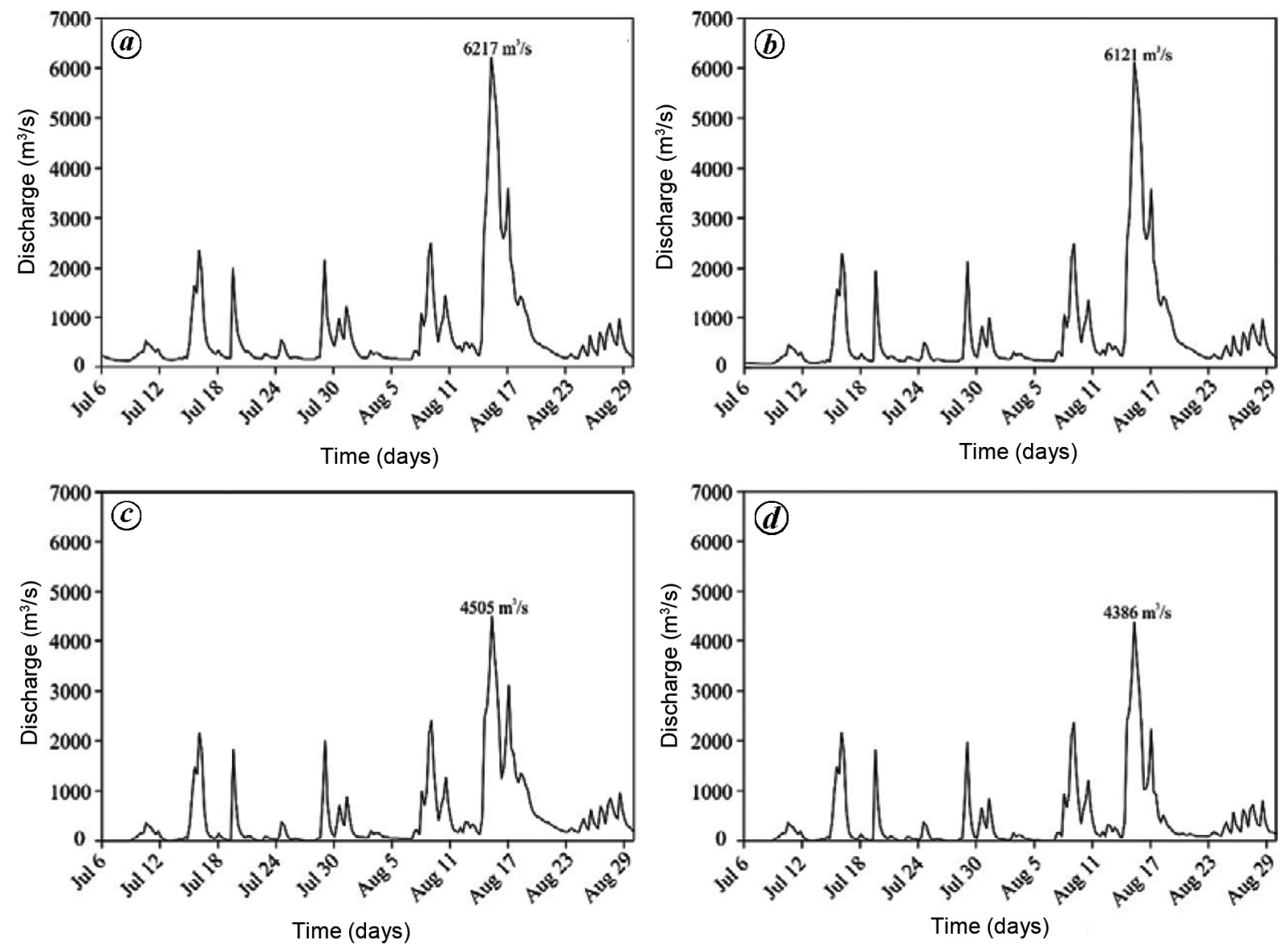

Figure 10. Flood hydrographs at L1 when reservoirs are at storage capacities (a) $85 \%,(\boldsymbol{b}) 75 \%,(\boldsymbol{c}) 50 \%$ and (d) $25 \%$ by the end of June 2018 with AMC-II conditions.

The simulation run corresponding to storage level at $75 \%$ resulted in a peak discharge of $4516 \mathrm{~m}^{3} / \mathrm{s}$ and $8340 \mathrm{~m}^{3} / \mathrm{s}$ (Figure $8 a$ and $9 a$ ) at $\mathrm{L} 1$ and $\mathrm{L} 2$ respectively, compared to a peak discharge of $5523 \mathrm{~m}^{3} / \mathrm{s}$ and $9965 \mathrm{~m}^{3} / \mathrm{s}$ (respectively for L1 and L2) for 85\% storage level (Figure $6 b$ and $c$ ). The reduction in storage capacity of reservoirs, from $85 \%$ to $75 \%$ through early release, helps reduce the peak flow at L1 by $18 \%$ and at L2 by $16 \%$. Similarly, the reduction in reservoir storage from $85 \%$ to $50 \%$ or $25 \%$ reduced peak discharge by $21 \%$ at both locations. The bank full discharge at L1 and L2 approximately being $3400 \mathrm{~m}^{3} / \mathrm{s}$ and $4200 \mathrm{~m}^{3} / \mathrm{s}$, it is apparent that the reservoir operation could not have helped in avoiding the flood situation. Further, the simulations with reservoirs at $50 \%$ and $25 \%$ of their gross storage capacities hardly showed any significant difference in the generated flows at both L1 (Figure $8 b$ and $c$ ) and L2 (Figure $9 b$ and $c$ ). Hence, the reported flows at downstream locations will be insensitive to the storage status of the reservoirs, if the reservoir is filled to less than $50 \%$ of its capacity.

On the other hand, the simulations clearly indicate that flood peaks could have been attenuated by an early release of reservoir storage (flood cushion up to 25\%) prior to the occurrence of the EREs, though to a maximum level of only $21 \%$. However, as the reservoirs are designed and currently operated for hydroelectric power generation, a policy that directs emptying the reservoir has critical limitations. The current reservoir operation policy is based on water conservation so as to maintain the reservoir levels close to FRL throughout the monsoon season to ensure maximum power generation. Therefore, it is suggested that one should revisit the operation rule curves of the reservoirs and derive fresh rule curves in order to operate the reservoirs not only as power reservoirs but also as flood control reservoirs. The goal of these rule curves should include minimization of flood damage besides maximization of benefit due to power generation.

In order to assess the effect of maintaining the reservoirs at $85 \%, 75 \%, 50 \%$ and $25 \%$ storage capacities at the end of June 2018, corresponding flow hydrographs were generated at L1 and L2 (Figures 10 and 11). Since June is the beginning month of ISMR, the antecedent moisture status was assumed to be of average conditions (i.e. AMC-II). It is noted that flood peak at L1 and L2 remained similar in this scenario $(85 \%$ storage at the end of June 2018) compared to run 2 (85\% storage at the end 

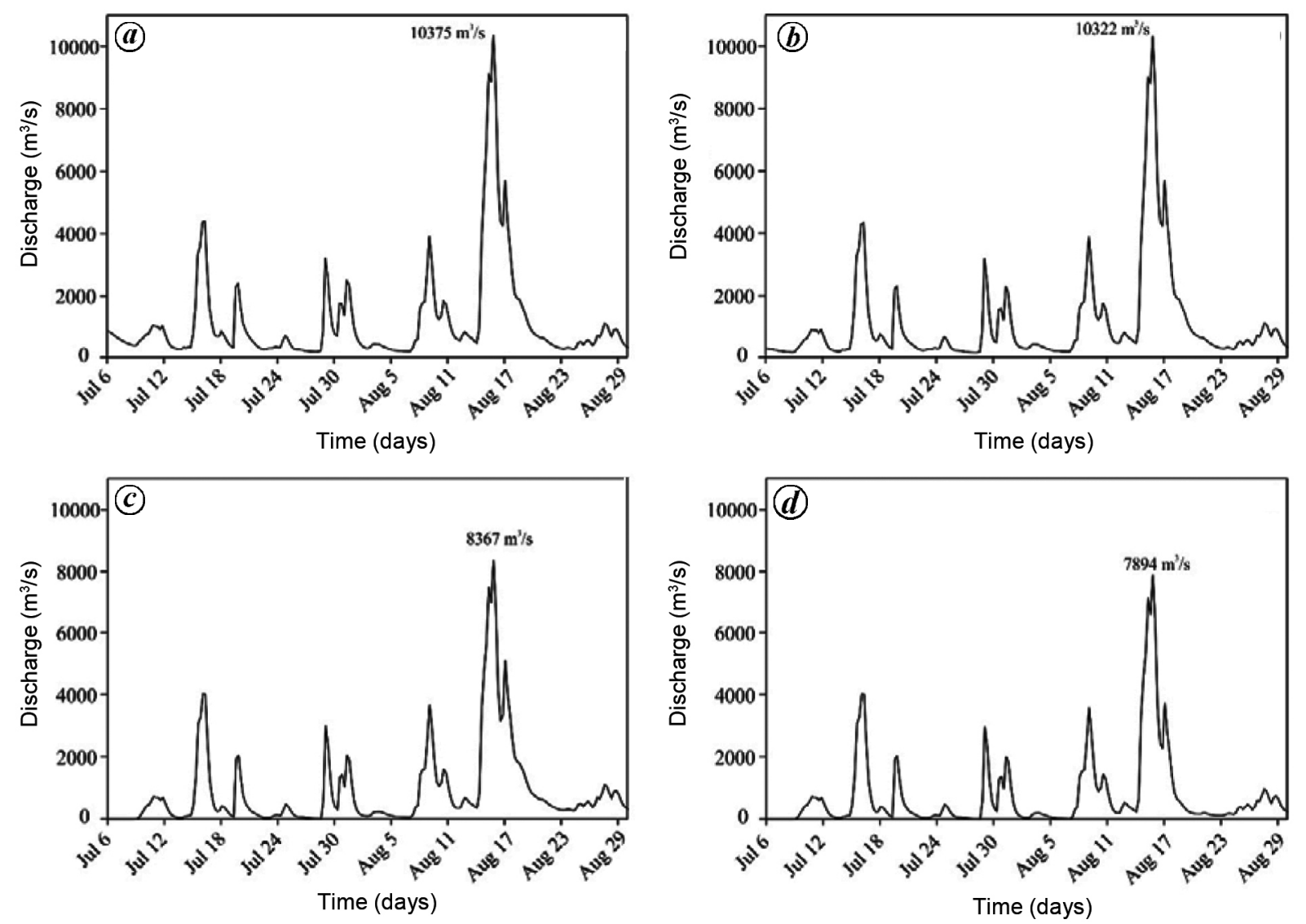

Figure 11. Flood hydrographs at L2 when reservoirs are at storage capacities (a) $85 \%,(\boldsymbol{b}) 75 \%,(\boldsymbol{c}) 50 \%$ and $(\boldsymbol{d}) 25 \%$ by the end of June 2018 with AMC-II conditions.

of July 2018). This is because of the continuous spell of rainfall (though not heavy) during the month of July 2018 , which resulted in minimal releases from the reservoir due to conservation operation. Consequently, the reservoirs attained near FRL storage by the end of July 2018. Hence, it would have been critical to maintain the flood cushion of $15 \%$ to $25 \%$ by the end of July rather than by the end of June.

\section{Remarks}

The role of dams in mitigating floods has been studied globally by various researchers/agencies. The California Flood Emergency Action Team report on the 1997 floods claimed that flood control dams in major river systems reduced deadly flood flows by half or more, saving lives and significantly reducing property damage (www. water.ca.gov). Considering the rivers of USA, the per cent of rivers with greater than $25 \%$ reduction in the median annual flood is $55 \%$ for large rivers, $25 \%$ for medium rivers and $10 \%$ for small rivers ${ }^{19}$. The analysis of 37 rivers in the United States to study the impact of dams in the annual peak flow of the rivers also showed a significant reduction in the average annual peak flow values between $7.34 \%$ and $95.14 \%$ (ref. 20). A comparison of the hydrographs simulated for the virgin condition (run 1) and the actual event in 2018 (run 2) suggests a $33 \%$ attenuation of peak flow at L1 and $17 \%$ at L2. Note that there are 11 reservoirs upstream of $\mathrm{L} 1$, whereas there are only 3 reservoirs upstream of L2 up to L1. Therefore, a major attenuation of the flood occurred by the interconnected reservoirs upstream of $\mathrm{L} 1$, and resulted in higher attenuation level compared to the attenuation at L2. The results in general indicate the positive role of dams/reservoirs in flood mitigation in the PRB, as is expected. Earlier studies had also observed that $41 \%$ of the net runoff of Periyar river (at downstream reaches) is reduced due to the construction of dams ${ }^{21}$, while another study $^{22}$ reported that the flood moderation and fairweather flow augmentation due to dams resulted in hydrologic alterations in PRB. In this premise it is evident that the dams in PRB did serve the flood moderation with its envisaged flood cushion, though the system is designed for conservation operation.

Historical rainfall data of the Kerala state indicate that maximum rainfall is experienced in June and July months, compared to August and September. Rainfall analysis of the state ${ }^{9}$ indicates that roughly $70 \%$ of the 
mean ISMR in Kerala (considering the period 18712012) occurs during June and July months, whereas the contribution during August month is less than 20\%. Moreover, the rainfall experienced during August and September shows relatively larger temporal variability (i.e. coefficient of variation $=41 \%$ and $53 \%$ respectively), compared to the monthly rainfall in June and July (i.e. $28 \%$ and $32 \%$ respectively). A frequency analysis of the rainfall in the PRB during the months of June and July indicated that the rainfall magnitude received in June 2018 had a return period of only 3 years, and July 2018 had a recurrence interval of 8 years. However, the August 2018 rainfall was found to be of 145 years return period. Note that the frequency analysis was conducted for the average rainfall for $\mathrm{PRB}$, using rainfall data of 55 meteorological stations in PRB with varying length of data record for 105 years (1901-2006). The study ${ }^{5}$ reported that the 1,2, and 3-day extreme rainfall in Kerala during August 2018 had return periods of 75, 200 and 100 years respectively. The extreme rainfall during the first 15 days of August 2018 in the catchment area of Idukki and Mullaperiyar dams had a return period of more than 500 years ${ }^{5}$. Though it appears to be exorbitant it is plausibly owing to uncertainties in the gridded rainfall information used for the analysis. Despite the uncertainty, it is obvious that the rainfall in August 2018 was of a very high recurrence interval.

As mentioned earlier, none of the dams/reservoirs in PRB has been designed for flood control purpose, but for hydropower/irrigation, and therefore the operation policy has been to maintain the reservoir levels close to FRL throughout the monsoon season to ensure maximum power generation. The PRB has experienced only two severe flood events in recent history, one in 1924 and the other in 1961. In 2013, downstream areas of Bhoothathankettu barrage, including the Cochin International Airport Ltd. were inundated due to release of water from Idamalayar dam. The frequency analysis of the historic annual flood discharge data recorded at L2 (during 19712018) indicated that the flood event of August 2018 had a return period of 142 years. The results suggest that the probability of EREs and associated flood event of the kind experienced in August 2018 in PRB is very small, and therefore any planned operation could not have helped in mitigating floods of such magnitude as the reservoir design and/or operation might not have considered such events.

In addition, accuracy of the forecasts is also important in reservoir operations. Currently, decision-making in the water resources and disaster management sector in India depends on the quantitative precipitation forecasts (QPF) from IMD. Though the accuracy of district level medium range rainfall forecast (up to 5-7 days in advance) is 75$85 \%$ in monsoon season (www.pib.nic.in/newsite/Print Release.aspx?relid=108707), the accuracy of QPF with regards to rainfall magnitude is low. On the other hand, accuracy of the medium range weather forecasts by IMD at higher lead times is greatly debated. The probability of detection (POD) of higher rainfall ( $>25 \mathrm{~mm} /$ day) at short range (3-day) or medium range (5-day) even with the ensemble of models is still low at about $20 \%$ to $30 \%$ only $^{23}$ with a large probability of false alarm ${ }^{24}$. As the operation of reservoirs for hydro-power or irrigation purposes has a huge economic benefit associated with it, further improvement in the reliability of QPF, especially those of EREs with a lead time of 3 to 7 days is extremely important. Therefore, improvement in the reliability of forecasting of EREs coupled with a good inflow forecasting system could help improve the management of reservoirs.

On the other hand, the link of the ERE that caused the devastating flood during August 2018 with the global climate change is also a concern. Many researchers have attributed climate change to an increase in EREs across the globe ${ }^{25-27}$. In the Indian context too, many researchers have observed significantly increasing trends in the frequency and the magnitude of EREs during ISMR $^{28-30}$. However, the underlying physics for the increased EREs over Indian region is still an enigma, as the researchers have proposed varied hypothese ${ }^{29-31}$. In addition, it is demonstrated that the occurrence of EREs during ISMR is mostly localized over the west coast, central parts of India and northeast India ${ }^{30}$. Therefore, developing a reliable early warning system, specifically for EREs, is a challenging task.

The experience during the August 2018 flood in Kerala underscores the significance of reviewing the flood management strategies and flood mitigation measures. The study suggests revisiting the rule curves of the reservoirs by considering dams as multi-purpose and multi-reservoir water resource systems, and developing integrated reservoir operation policies. The goal of the modified rule curves should include minimization of flood damage

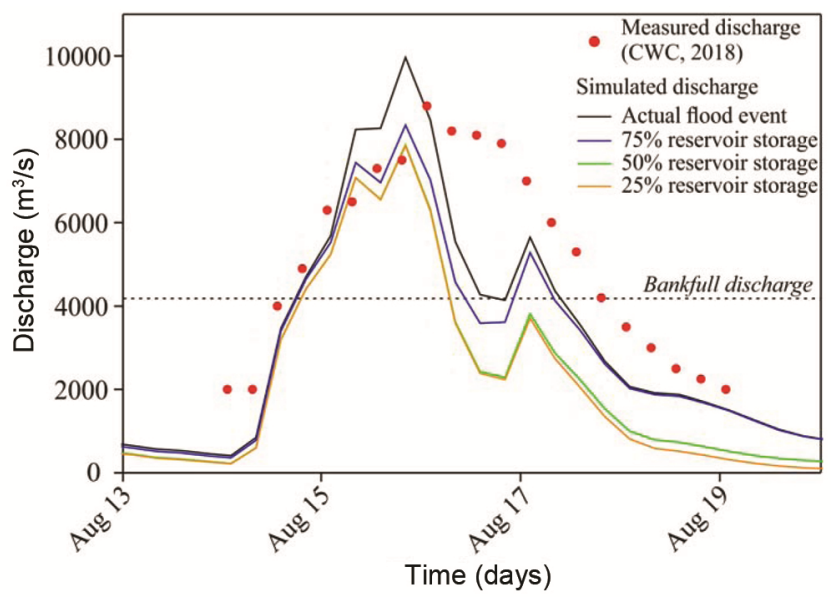

Figure 12. Comparison of the simulated peak discharge (part of the hydrographs during the flood peak) for different reservoir storages at Neeleswaram, along with the measured discharge during the flood event. 
besides maximization of benefits due to power generation and irrigation. This aspect needs in-depth studies on improving weather forecasts, reservoir inflow forecasts and multi-reservoir/multi-objective operational rule sets. Studies on these aspects need to be initiated with highest priority to be better prepared to effectively manage such EREs in the future.

\section{Summary and conclusion}

The extensive flooding during August 2018 in Kerala (India) due to two consecutive EREs (during 8-10 and 14-19 August 2018) affected millions of people, and caused substantial damages to infrastructure as well as the physical environment. The extraordinary combination of the occurrence of the EREs, along with near FRL reservoir storages, made the situation challenging to manage, and coerced the authorities to open the gates of most of the dams in the state to release water. Hence, the role of dams and its operations in causing/mitigating the flood has been criticized and debated in the scientific, social and political contexts, and the discussions explicitly held the reservoir operations practiced during the flood and the lack of adequate warnings responsible for the paroxysm. One of the major river basins that was affected by the flood was PRB, which consists of 17 dams/barrages that are interconnected. An analysis of the rainfall record indicated that the rainfall received in PRB during August 2018 had a return period of 145 years. Similarly, the observed flood on record during August 2018 in PRB (Neeleswaram; location 2) had a recurrence interval of 142 years. In this premise, the question, whether an early release of the water stored in the PRB reservoirs could have helped or not in attenuating flood peaks, still remains unexplained. Hence, a modelling exercise to simulate the role of dams as well as reservoir operations in causing the flood of August 2018 was performed using HEC-HMS. The study analysed different scenarios with combinations of reservoir storages $(85 \%, 75 \%, 50 \%$ and $25 \%)$ at different time periods (end of June and end of July), along with different AMCs (average and wet conditions).

The model simulated the flood discharge fairly well, showing insignificant temporal offsets. The simulated and observed peak flows to Idukki reservoir (upstream of PRB) were 2763 and $2532 \mathrm{~m}^{3} / \mathrm{s}$ respectively. Similarly, the maximum discharge simulated at Neeleswaram was $9965 \mathrm{~m}^{3} / \mathrm{s}$ against the measured value of $8800 \mathrm{~m}^{3} / \mathrm{s}$. The flood hydrograph between PRB without dams (virgin simulation) and the actual flood event (simulation with reservoirs at storage capacity $85 \%$ by the end of July 2018) showed reduced peak discharge at location L1 by $33 \%$ (immediately downstream of Idduki), and at location L2 by $17 \%$ (at Neeleswaram), indicating the positive role of dams in attenuating the flood magnitude. The study also indicated that the major share of the total flood flow was by Perinjankutty $\left(3500 \mathrm{~m}^{3} / \mathrm{s}\right)$, which is a near uncon- trolled tributary, while the controlled releases from Iduk$\mathrm{ki}$ had contributed only $1860 \mathrm{~m}^{3} / \mathrm{s}$. It is noted that Idamalayar reservoir releases, along with the free catchment downstream of the reservoir contributed $2828 \mathrm{~m}^{3} / \mathrm{s}$ of the total flood, while Muthirapuzha basin contributed $2037 \mathrm{~m}^{3} / \mathrm{s}$. The results indicated that the role of releases from the major reservoirs in the PRB to cause the flood havoc was less. It is also observed that the antecedent soil moisture condition had hardly any role in controlling the flood peak of the basin as the difference in the flood magnitude between AMC-II and AMC-III conditions was less than $10 \%$. Note that the soil moisture condition in general reach AMC-III by the end of June in most years.

The results suggest that the peak flow at Neeleswaram could have been curtailed by early release of the reservoir storage and making the end of month storage less than $85 \%$ of the storage capacity. However, this strategy has critical limitations as these reservoirs are designed for hydropower generation, and current reservoir operation policy is based on water conservation so as to maintain the reservoir levels close to FRL throughout the monsoon season to ensure maximum power generation. However, emptying the reservoir to $75 \%$ of the total storage by the end of July suggested a reduction in peak at Neeleswaram, though only $16 \%$. A controlled storage of $50 \%$ or $25 \%$ in all the reservoirs suggested a peak attenuation by $21 \%$ from $9965 \mathrm{~m}^{3} / \mathrm{s}$. The simulated flood peak (part of the hydrograph during the flood peak) corresponding to different reservoir storages $(85 \%, 75 \%, 50 \%$ and $25 \%$ ) along with the observed hydrograph at Neeleswaram is presented in Figure 12 for a direct comparison. With the bank full discharge at Neeleswaram approximately being $4200 \mathrm{~m}^{3} / \mathrm{s}$, it is apparent that the reservoir operation could not have helped in avoiding the flood situation. In addition, the reliability of the rainfall forecast at higher lead times was also a concern for the reservoir operation. Further, as the probability of EREs of this kind in the month of August in PRB is very small $(0.6 \%)$, any planned operation could not have helped in mitigating floods of such magnitude as the reservoir design might not have considered such events.

The present analysis of the August 2018 flood in PRB, suggests revisiting the rule curves of the reservoirs by considering the dams as multi-purpose and multireservoir water resources systems, and developing integrated reservoir operation policies so as to maintain the balance between flood control and other system objectives, such as hydropower generation and irrigation. However, it may be noted that the success of flood management exclusively depends on the accuracy of prediction of EREs at higher lead times.

1. Frei, C., Davies, H. C., Gurtz, J. and Schär, C., Climate dynamics and extreme precipitation and flood events in Central Europe. Integr. Assess., 2000, 1, 281-300.

2. Roxy, M. K. et al., A threefold rise in widespread extreme rain events over central India. Nat. Commun., 2017, 8, 708. 
3. Luo, P. et al., Flood inundation assessment for the Hanoi Central Area, Vietnam under historical and extreme rainfall conditions. Sci. Rep., 2018, 8, 12623.

4. CWC, Kerala Floods of August 2018, Central Water Commission, New Delhi, 2018.

5. Mishra, V., Aaadhar, S., Shah, H., Kumar, R., Pattanaik, D. R. and Tiwari, A. D., The Kerala flood of 2018: combined impact of extreme rainfall and reservoir storage. Hydrol. Earth Syst. Sci. Discuss., 2018; https://doi.org/10.5194/hess-2018-480.

6. Sankar, G., Monsoon fury in Kerala-a geo-environmental appraisal. J. Geol. Soc. India, 2018, 92, 383-388.

7. Abe, G., Hydrologic alterations due to hydroelectric projects in the Periyar Muvattupuzha River System, Kerala, India. Karunya University, Coimbatore, 2014.

8. Nair, A., Ajith Joseph, K. and Nair, K. S., Spatio-temporal analysis of rainfall trends over a maritime state (Kerala) of India during the last 100 years. Atmos. Environ., 2014, 88, 123-132.

9. Thomas, J. and Prasannakumar, V., Temporal analysis of rainfall (1871-2012) and drought characteristics over a tropical monsoondominated state (Kerala) of India. J. Hydrol., 2016, 534, 266-280.

10. Soman, K., Geology of Kerala, Geological Society of India, Bangalore, 2002.

11. Maya, K., Babu, K. N., Padmalal, D. and Seralathan, P., Hydrochemistry and dissolved nutrient flux of two small catchment rivers, south-western India. Chem. Ecol., 2007, 23, 13 27.

12. Shyam, T. S. A., Ground Water Information Booklet of Ernakulam District, Kerala State, Thiruvananthapuram, 2013.

13. Singadurai, S., Ground Water Information Booklet of Idukk District, Kerala State, Thiruvananthapuram, 2013.

14. Halwatura, D. and Najim, M. M. M., Application of the HECHMS model for runoff simulation in a tropical catchment. Environ. Model. Softw., 2013, 46, 155-162.

15. Young, C. C., Liu, W. C. and Wu, M. C., A physically based and machine learning hybrid approach for accurate rainfall-runoff modeling during extreme typhoon events. Appl. Soft Comput., 2017, 53, 205-216.

16. Zope, P. E., Eldho, T. I. and Jothiprakash, V., Impacts of land useland cover change and urbanization on flooding: a case study of Oshiwara River Basin in Mumbai, India. Catena, 2016, 145, 142 154

17. Gumindoga, W., Rwasoka, D. T., Nhapi, I. and Dube, T., Ungauged runoff simulation in Upper Manyame Catchment, Zimbabwe: application of the HEC-HMS model. Phys. Chem. Earth, 2017, 100, 371-382.

18. NBSSLUP, Kerala Soils. National Bureau of Soil Survey and Land Use Planning, Bangalore, 1996.

19. Fitzhugh, T. W. and Vogel, R. M., The impacts of dams on flood flows in the United States. River Res. Appl., 2011, 27, 1192-1215.

20. Mei, X., Van Gelder, P. H. A. J. M., Dai, Z. and Tang, Z., Impact of dams on flood occurrence of selected rivers in the United States. Front. Earth Sci., 2017, 11, 268-282.
21. Abdu Rahiman, K. U., Dwarakish, G. S. and Kawal, B. M., Changes in hydrology and coastal sedimentation by dams - a case study. ISH J. Hydraul. Eng., 2009, 15, 51-64.

22. Abe, G. and Joseph, J. E., Changes in streamflow regime due to anthropogenic regulations in the humid tropical Western Ghats, Kerala State, India. J. Mt. Sci., 2015, 12, 456-470.

23. Durai, V. R. and Bhardwaj, R., Improving precipitation forecasts skill over India using a multi-model ensemble technique. Geofizika, 2013, 30, 119-141.

24. Durai, V. R., Bhardwaj, R., Bhowmik, S. K. R. and Rao, Y. V. R., Verification of quantitative precipitation forecasts from operational ensemble prediction systems over India. Mausam, 2015, 66, 479-496.

25. Easterling, D. R., Evans, J. L., Groisman, P. Y., Karl, T. R., Kunkel, K. E., and Ambenje, P., Observed variability and trends in extreme climate events: A brief review. Bull. Am. Meteorol. Soc., 2000, 81, 417-426.

26. Frich, P. et al., Observed coherent changes in climatic extremes during the second half of the twentieth century. Clim. Res., 2002, 19, 193-212.

27. Trenberth, K. E., Dai, A., Rasmussen, R. M. and Parsons, D. B., The changing character of precipitation. Bull. Am. Meteorol. Soc., 2003, 84, 1205-1218.

28. Goswami, B. N., Venugopal, V., Sangupta, D., Madhusoodanan, M. S. and Xavier, P. K., Increasing trend of extreme rain events over India in a warming environment. Science, 2006, 314, 14421445 .

29. Ajayamohan, R. S., Merryfield, W. J. and Kharin, V. V., Increasing trend of synoptic activity and its relationship with extreme rain events over central India. J. Clim., 2010, 23, 10041013.

30. Pattanaik, D. R. and Rajeevan, M., Variability of extreme rainfall events over India during southwest monsoon season. Meteorol. Appl., 2010, 17, 88-104.

31. Rajeevan, M., Bhate, J. and Jaswal, A. K., Analysis of variability and trends of extreme rainfall events over India using 104 years of gridded daily rainfall data. Geophys. Res. Lett., 2008, 35, L18707.

ACKNOWLEDGEMENTS. The authors thank Dr George Abe, Chief Scientist and Head, Centre for Water Resources Development and Management, Kottayam Sub Centre for providing the historic rainfall data. The Kerala State Electricity Board and Cochin International Airport Ltd also deserve special appreciation for the help rendered during the field campaign for the study. We also extend our thanks to the residents of the flood affected areas at Cheruthoni, Karimban, Neendapara, Kalady, Alwaye and North Paravur, for their cooperation in data collection during the field visit.

Received 31 October 2018; revised accepted 6 November 2018

doi: $10.18520 / \mathrm{cs} / \mathrm{v} 116 / \mathrm{i} 5 / 780-794$ 